\title{
THE ASSOCIATION BETWEEN BODY MASS INDEX, RELIGION INDEX, MEDIA, AND BODY IMAGE IN ADOLESCENTS
}

\author{
Widana Primaningtyas, Heni Hastuti, \\ Anak Agung Alit Kirti Estuti Narendra Putri \\ Medical Faculty, Sebelas Maret University
}

\begin{abstract}
BACKGROUND: Adolescents experience bio-psychosocial change in their developmental stages. These changes influence their perception about their body look. Some start to dislike their appearance. Someone's religiosity may protect them from the negative impact of the environment. Meanwhile, the mass media campaign about "slim ideal" for women and "shape and muscle" for men, is massive. This study aimed to examine the association between body mass index (BMI), religiosity, mass media, and body image in adolescents.
\end{abstract}

SUBJECT AND METHODS: This was a cross sectional study. A sample of 116 students was selected at random for this study from one public and one private senior high school in Surakarta, Indonesia. The dependent variable was negative body image. The independent variables included body mass index (BMI), religiosity, and exposure to "slim ideal" mass media. Body image was measured using Body Shape Questionnaire. Religiosity was measured using Duke University Religion Index Questionnaire. The data was analyzed using linear regression model.

RESULTS: BMI $(b=3.22 ; 95 \% \mathrm{CI} 2.08$ to 4.36 ; $\mathrm{p}<0.001)$ and exposure to "slim ideal" mass media ( $b=16.35 ; 95 \% \mathrm{CI} 1.92$ to $30.78 ; \mathrm{p}=0.027$ ) had positive association with negative body image, and it was statistically significant. Religiosity ( $b=-3.10 ; 95 \% C I-11.86$ to $5.64 ; p=0.483$ ) had negative association but statistically not significant with negative body image.

CONCLUSION: BMI and exposure to "slim ideal" mass media have positive association with negative body image in adolescents.

Keywords: body image, adolescents, Body Mass Index, religion index, media. 